\title{
TRAMAS DEL RECLUTAMIENTO Y PARTICIPACIÓN DE NIÑOS EN EL CONFLICTO ARMADO COLOMBIANO*
}

\author{
NARRATIVE PLOTS OF RECRUITMENT AND PARTICIPATION OF CHILDREN \\ IN THE COLOMBIAN ARMED CONFLICT
}

\author{
ElizABETH TORRES-PUentes**
}

\section{Resumen}

Objetivo. Este artículo presenta parte de los antecedentes de una investigación cuyo objetivo es analizar la trama narrativa de la vinculación y participación de niños en grupos armados colombianos en distintos periodos. Metodología. Se soporta en el análisis narrativo, por ello para el acopio de antecedentes se revisó la literatura académica que hace énfasis en el recorrido por la vinculación y participación de menores a partir de algunos relatos de niños que fueron reclutados en los grupos armados desde la Guerra de los Mil Días hasta los grupos paramilitares de los noventa. Resultados. Se reconoce que el fenómeno de la vinculación de niños no solo es consecuencia del conflicto, también es una consecuencia del abandono institucional a niveles social, económico y político de la infancia. Conclusión. En los relatos estudiados se identifican elementos temporales y espaciales que configuran la trama narrativa de cada una de las guerras vividas en Colombia.

Palabras clave: vinculación de menores, trama narrativa, conflicto armado.

\begin{abstract}
Objective. This article presents part of the background of a research whose objective was to analyze the narrative plot of the connection and participation of children in Colombian armed groups in different periods. Methodology. It is supported in the narrative analysis, reason why for the collection of the history, academic literature was reviewed emphasizing in the journey through the binding and participation of minors from some stories of children who were recruited in the armed groups from the War of the Thousand Days to the paramilitary groups of the nineties. Results It is recognized that the phenomenon of child binding is not only a consequence of the conflict but also a consequence of the institutional, social, economic and political abandonment of childhood. Conclusion. Temporal and spatial elements are identified in the stories studied that make up the narrative plot of each one of the wars lived in Colombia.
\end{abstract}

Key words: child binding, narrative plot, armed conflict.

\footnotetext{
* Este artículo expone parte de los antecedentes de la investigación titulada Construcción de temporalidades en las narrativas de niños, niñas y adolescentes, desvinculados de los grupos armados colombianos que retornan a la escuela, orientada por la Doctora Marieta Quintero, en el marco del Doctorado Interinstitucional en Educación de la Universidad Distrital Francisco José de Caldas, en la línea de investigación Narraciones, argumentaciones, justificaciones y discurso en la formación ética y política del énfasis de lenguaje y educación.

${ }^{* *}$ Universidad Pedagógica Nacional. Bogotá, Colombia. E-mail. etorresp@pedagogica.edu.co

(D) orcid.org/0000-0002-3642-0571 Google Scholar
} 


\section{Introducción}

\section{La trama narrativa: insumo teórico para el análisis}

En el marco de la investigación de la que emerge este artículo, se han considerado las tesis de Ricoeur (2010), quien afirma que hay un vínculo estrecho entre narrativa y experiencia humana. Para este autor, la función narrativa está constituida por una estructura lingüística cuyo referente es la temporalidad, lo que quiere decir que el lenguaje permite seleccionar y organizar la narrativa a partir de unidades de tiempo, discurso y significación. También reconoce que existen distintas formas de organizar el tiempo que llevan a considerar distintos grados de temporalidades. Así, encontramos el “tiempo vulgar”, que corresponde a la sucesión lineal de instantes; sin embargo, el tiempo del relato supera esta representación, pues da cuenta del "estar en el tiempo" y activa la memoria, para traer al presente y al futuro acontecimientos del pasado. Así, en la trama narrativa es donde habita el vínculo entre narrativa y experiencia humana, y es la triple mímesis el recurso para dar cuenta de ella.

Ricoeur (2010) considera que la trama en la narración se constituye de acciones, acontecimientos y agentes, con sus circunstancias y características particulares. Esta trama es resultado de la síntesis de lo heterogéneo y se configura gracias a la unidad temporal encargada de otorgarle extensión, límite y orden. Para el autor, el tiempo está presente tanto en la configuración de la estructura de la trama como en los hechos históricos, pues todo acontecimiento histórico posee una trama.

El filósofo francés señala que se hace necesaria una "operación configurativa” que conecte un “antes” con un "después”. Esta operación da lugar a la triple mímesis, sin la cual no es posible construir una trama. La triple mímesis es un recurso para dar cuenta de la trama, que informa de la permanencia y cambio de la vida a partir de las múltiples experiencias. Así, la trama está constituida por una prefiguración, una configuración y una refiguración, todas ellas en una relación no escindible. La relación entre las tres mímesis configura una trama, que a su vez media entre la narración y la temporalidad. La primera mímesis, es decir la pre-configurativa, hace directa referencia al mundo de la acción y se compone de los siguientes elementos:

Rasgos estructurales: la acción se refiere a la organización de los hechos en tanto son acciones humanas; los motivos permiten responder a la pregunta ¿qué?, y sirven para identificar la acción; el agente es aquel capaz de producir acontecimientos, pero además se reconoce en él una intensión y un deseo.

Rasgos simbólicos: la regla proporciona los códigos de descripción e interpretación; la norma es el sentido prescriptivo de la regla; los símbolos, por su parte, señalan las estructuras propias de las reglas y las normas en contextos particulares. 
Tramas del reclutamiento y participación de niños en el conflicto armado colombiano

Rasgos temporales: la intratemporalidad está relacionada con la idea de contar con el tiempo y el cuidado de sí en la vida cotidiana. El ser-en-el tiempo es preocuparse por el ahora y por el paso del tiempo. Los rasgos temporales se identifican en la narración que se hace en el ahora del pasado.

Por su parte la mímesis II es mediadora entre la mímesis I (pre-configuración) y III (reconfiguración) por tres razones:

Mediación entre los acontecimientos individuales que hacen inteligible la historia: quiere decir que una serie de acontecimientos o incidentes hacen que la historia tenga sentido, pues otorgan a la misma una intriga que hace que los acontecimientos individuales sean imprescindibles para que la historia sea completa.

Mediación entre los diferentes componentes de la trama: la mímesis II integra factores heterogéneos (agentes, medios, interacciones, circunstancias, resultados inesperados, etc.). Estos factores se integran en la concordancia-discordancia que constituye la función mediadora de la trama. La concordancia, según Ricoeur (2010), tiene tres características: la totalidad, que garantiza una organización dada por la secuencia principio, medio y fin; la extensión, que garantiza que el relato tenga un límite, sin que se deje de respetar la totalidad; y la completitud, que es producto de las dos anteriores, permitiendo que emerja lo inteligible de lo accidental y de los cambios intempestivos.

En consonancia con lo anterior, la discordancia presenta tres características que, juntas, dice Ricoeur (2010), llevan a un alto grado de tensión en la función de lo paradójico y del encadenamiento causal de la sorpresa y la necesidad: la peripecia vinculada con la sorpresa, con lo repentino que implica un punto de inflexión en el relato; la agnición que refiere al reconocimiento de una personalidad ignorada; y el lance patético que representa el cambio de sentido, que se da a partir del reconocimiento de las emociones trágicas. El autor propone que existen dos tipos de tramas, una cronológica que da cuenta de la orden de los acontecimientos y otra no cronológica que instala una transformación de los acontecimientos.

Finalmente, la tercera mímesis refiere a la resignificación de la experiencia. En esta el sujeto reflexiona sobre preconcepciones y ordenamientos que le dio a los acontecimientos en la mímesis II y se restituye la acción al tiempo vivido del lector. La mímesis III "marca la intersección del mundo del texto y del mundo del oyente o del lector: intersección, pues, del mundo configurado por el poema y del mundo en el que la acción efectiva se despliega y despliega su temporalidad específica" (Ricoeur, 2010, p. 140), es decir, que es el lector, o quien escucha, el que recompone y organiza los hechos para su comprensión. Esta experiencia de reconfiguración se da entre la realidad del lector y otra realidad posible (la del relato); a esto llama Ricoeur, aludiendo a Gadamer, la fusión de horizontes. Así, el que interpreta dota 
de sentido al relato, lo resignifica. El proceso de resignificación requiere que quien escucha el relato parta de sus experiencias propias y reconozca los símbolos inmersos en la narración. El hacer lectura de esos símbolos siempre implica elementos imaginarios que hacen que quien lee o escucha un relato represente en sí mismo el texto de forma distinta. Con la mímesis III, Ricoeur (2010) afirma que la construcción de la trama es un esfuerzo conjunto entre el relato y quien lo interpreta.

\title{
Metodología
}

\section{Análisis narrativo, una ruta metodológica}

Para consolidar los antecedentes de la investigación de los cuales se da cuenta en este artículo, se consideró el análisis narrativo como estrategia metodológica para examinar los relatos de niños que se vincularon en cada uno de los periodos que marcaron el conflicto en el último siglo en Colombia.

En este orden de ideas, para Bolívar (2002) un ejercicio narrativo,

\begin{abstract}
Reconoce estudios basados en casos particulares (acciones y sucesos), pero cuyo análisis (narrativo, en sentido estricto) produce la narración de una trama o argumento, mediante un relato narrativo que torne significativos los datos. Aquí no buscamos elementos comunes, sino elementos singulares que configuran la historia. (p. 13)
\end{abstract}

Así, el análisis narrativo que se presenta en este artículo retoma las experiencias tamizadas por los relatos de las propios sujetos que siendo niños estuvieron vinculados a la guerra, es decir, muestra las tramas que han configurado la vinculación y participación de niños en las actividades bélicas propias del conflicto armado colombiano. Para ello, metodológicamente, se usó la estrategia de sistematización del análisis narrativo propuesta por Quintero (2010), en la que se distinguen cuatro momentos:

Momento 1. Registro de codificación. Consiste en construir códigos de identificación del perfil de cada una de las narrativas.

Momento 2. Nivel textual: pre-concepción de la trama narrativa. En este momento se construye una red con los aspectos que conforman la trama (acontecimientos, acciones o experiencias). Se consideran las temporalidades y las especialidades teniendo en cuenta los hechos codificados en el momento 1 . 


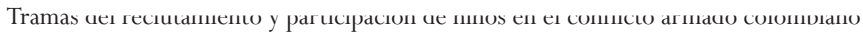

Para el análisis de las temporalidades, se ha considerado que el tiempo calendario corresponde a su interpretación lineal en unidades consecutivas de medición (días, meses, años, etc.); también se puede encontrar este tipo representado en el uso de adverbios temporales (siempre, a veces, en ocasiones, etc.). El tiempo de la experiencia,

Se refiere a la vivencia subjetiva o a las experiencias que nos indican las potencialidades del sujeto (yo puedo, yo hago..., etc.), así como la vida precaria (sufrimiento, humillación, dolor, entre otros), pero también el establecimiento de vínculos con los otros (contar con...). Este tiempo Ricoeur lo denomina 'tiempo del cuidado'. (Quintero, 2010, p. 7)

El tiempo histórico corresponde a la huella que deja la experiencia en los sujetos.

En cuanto a la espacialidad, Quintero (2010) afirma que

Se denomina espacio de coordenadas a todos aquellos lugares posibles de ser localizados y descritos en un plano objetivo (ciudades, barrios, calles, lugares, entre otros). En un sentido más amplio, los espacios se relacionan con el mundo subjetivo, es decir con representaciones y mundos simbólicos que hacen posible la "memoria de los lugares". (p. 7)

Momento 3. Nivel contextual de la trama narrativa. En este momento, el análisis se centra en la fuerza narrativa dada por el sujeto de la enunciación a sus acciones. Según Quintero (2010)

Esta fuerza narrativa se entiende como el uso comunicativo y/o expresivo empleado por el sujeto de la enunciación para referirse a lo que con "el lenguaje hace" y a "lo que hace con lo que dice". En otras palabras, con el lenguaje hacemos y decimos cosas, lo que implica una correspondencia entre lenguaje y mundo; correspondencia que incluye al "Otro" el cual hace parte de mi acción social y de "mi mundo subjetivo". Desde nuestro nacimiento hemos sido arrojados a las redes de interlocución o redes narrativas las cuales re-estructuramos a lo largo de nuestra vida por nuestras relaciones con los “Otros". (p. 9)

En este momento se identifica a los sujetos que han hecho la acción y han vivido los acontecimientos, por lo que se ubican atributos del sujeto relacionados con juicios, imputaciones o responsabilidades y potencialidades (yo puedo).

Los atributos del sujeto relacionados con juicios, remiten a los siguientes interrogantes:

¿Qué dice el agente de sí mismo?, ¿qué dice el agente de los otros?, ¿por qué hace lo que hace?, ¿qué lo lleva a hacer esto o aquello?, ¿qué símbolos usa para expresar su identidad y la de los otros?, ¿qué dice 
que ha hecho en contra o en favor de los otros?, ¿cuáles son los lazos de solidaridad?, ¿cuáles son las acciones valoradas como injustas, justas o adecuadas? (Quintero, 2010, p. 14)

Por su parte, los atributos del sujeto relacionados con las imputaciones o responsabilidades, pueden estar orientados por los siguientes interrogantes:

¿Cuál es la responsabilidad acerca de lo que se hizo?, ¿por qué lo hizo?, ¿cuáles son los grados de aprobación y desaprobación de sus acciones?, ¿qué es lo que le mueve habitualmente a comportarse así? Es decir, ¿cuáles son las iniciativas que lo motivaron a la acción?, entre otros. (Quintero, 2010, p. 14)

Finalmente, los atributos del(os) sujeto(s) relacionados con sus potencialidades (yo puedo) se refieren a la capacidad de iniciar algo nuevo. Entre otros interrogantes tenemos ¿qué puede hacer?, ¿qué cosas sabe hacer?, ¿cómo puede iniciar algo nuevo (espontaneidad)?

Momento 4. Nivel metatextual: reconfiguración de la trama narrativa. En este momento se hace una "nueva lectura" a partir de los momentos anteriores, donde se reconfigura la experiencia. Según la autora

En este nivel la polifonía discursiva guía la escritura en la que se reconfigura la trama narrativa confiriéndole a la narrativa su carácter de pluralidad, porque nos revelamos como sujetos narrativos irreductibles e inconfundibles. En este nivel, la polifonía da cuenta de que las narrativas no son simples historias, sino un conjunto interrelacionado de creencias, normas, ideologías las cuales son reveladas por el investigador y narradas en trama narrativa reconfigurada. (Quintero, 2010, p. 15)

En este momento, se construye un texto donde la voz que se privilegia es la del sujeto que vive la experiencia, quien prefigura y configura el relato; para el caso del presente estudio, nos referimos a la experiencia del niño reclutado en un grupo armado, pero esa experiencia es reconfigurada por el investigador.

A partir de la estrategia de sistematización para el análisis narrativo, se analizó la trama de algunos relatos de niños vinculados a los grupos armados, en diferentes épocas de conflicto armado en Colombia. Así, se han identificado los siguientes elementos, fundamentales comprender para la trama:

- Los atributos que corresponden a cada época: hechos particulares de cada una de las confrontaciones, las circunstancias que dieron lugar a los hechos, los medios con los que 
Tramas del reclutamiento y participación de niños en el conflicto armado colombiano

se realizaron y las consecuencias esperadas e inesperadas (contingencias).

- Los atributos del personaje: en este caso, las caracerísticas de los niños que se vincularon y participaron de los grupos armados en cada una de las épocas.

- Las temporalidades: tiempo calendario, tiempo humano y tiempo histórico.

- La espacialidad: espacios de coordenadas y espacios simbólicos.

Para determinar la periodización se tuvieron en cuenta los cinco intervalos que propone Pécaut (2006) para el conflicto armado colombiano: 1899-1902, Guerra de los Mil Días; 1920-1940, consolidación del bipartidismo; 1945-1964, gaitanismo y violencia; 1964-1980, auge guerrillero; y 1980-2005, narcotráfico y paramilitares.

\section{Resultados}

\section{Elementos para la discusión: la permanencia de los niños en la guerra}

Como ya se ha dicho en parte de los antecedentes de la investigación realizada, se tuvieron en cuenta relatos de niños que fueron vinculados a los diferentes grupos armados gracias a la literatura publicada en las últimas décadas, en los periodos aportados por Pécaut (2006); a estas narraciones se les ha hecho un análisis narrativo desde las consideraciones de Quintero (2010), lo que da lugar a la siguiente clasificación.

\section{Los niños soldados de la guerra de los mil días}

La Guerra de los Mil Días se ha considerado como la antesala a las guerras bipartidistas. La principal consecuencia de esta guerra fue la débil infraestructura con la que quedó el país, lo que provocó, entre otros factores, la separación de Panamá en 1903.

En cuanto a los atributos de los niños como personajes de esta trama, Jaramillo (2007) reconoce que los niños que se vinculaban a los grupos armados ostentaban valentía y arrojo, eran considerados como adultos pequeños con cualidades significativas para la guerra, pues su agilidad, viveza, sumisión ante las órdenes y su poco o nulo consumo de alcohol, además de su valentía frente a las tareas que implicaban riesgo, eran cualidades con las que no contaban los adultos.

Jaramillo (2007) reconoce que los niños de esta época eran reclutados para la guerra ya fuera en compañía de sus padres, quienes también se enlistaban como conscriptos llevados a la fuerza, y otros "inducidos por el fervor político, unido a la imagen idealizada de la guerra y de los hombres que la hacían” (p. 225). Este autor, respecto al reclutamiento forzado, aporta: 
La forma más productiva y corriente de reclutamiento fue los llamados encierros de plaza o reclutamiento con lazo, modalidad que se cumplía por medio de acciones imprevistas, en las que grupos armados cercaban las plazas de los pueblos en día de mercado y a las horas de mayor afluencia, tomando allí a todos los que estimaran eran propios para llevar a las filas, acto que se cumplía de inmediato sin que mediara aviso a sus familiares. Los escogidos normalmente eran amarrados con lazos y sacados hacia los campamentos en interminables y tristes filas, sin importar los gritos desesperados de las madres o familiares. (Jaramillo, 2007, p. 237)

En el apartado anterior, se observa que hay una espacialidad marcada en la práctica de la vinculación, pues esta se hace en lugares públicos, abiertos y de aglomeración de sujetos aptos para la guerra. Sin embargo, en cuanto a los atributos de los personajes, se podría decir que, en la medida que son forzados a hacer parte del grupo armado, en primera instancia, no se identifican con los ideales de determinado grupo.

Respecto a la temporalidad, propia de la trama de esta época, un aspecto a destacar es la edad de los niños (entre 10 y 17 años) en relación con las tareas que se cumplían (Jaramillo, 2007):

Como espías informadores y mensajeros. Esta tarea la podían hacer niños de hasta 7 años. No implicaba una confrontación directa en el combate, pero sí una responsabilidad importante dados los contenidos de los mensajes que transportaban.

Como ordenanzas. Esta tarea además de implicar menor riesgo, daba ciertos privilegios para los niños que la ejecutaban, como mejor comida, mayor libertad, mayor respeto del resto de la tropa y la posibilidad de ser temidos. Los ordenanzas se encargaban de estar al cuidado de las pertenencias de su jefe, llevarle la comida, hacer las veces de mandadero y cuidar de las bestias y los aperos. Para el caso de las guerras civiles, Jaramillo (2007) presenta la narración de Domingo Herrera, a propósito de su vinculación como ordenanza cuando era niño:

Once años tenía cuando me tomaron los conservadores para que
militara con ellos y, a pesar de ser conocida mi familia con la de los jefes
conservadores, éstos no me dejaron libre. Ese día sin instrucción alguna
me dieron un Remington, que era el arma más popular del ejército,
provisto de una cabuya para colgarlo, y de una vez me hicieron formar
con la tropa. Yo, como todos los chinos, a punta de poner cuidado en
los desfiles y en las entradas de los ejércitos, conocía los principales
movimientos y órdenes de mando, por lo que cuando me formaron las
hice muy bien, a lo que los soldados conservadores me dijeron: ¿Cómo les
parece el jijueputa este?, lo veterano que es. ¿Qué fierita iría a salir este
bergajo? Acuartelados ya en San Juan (se refiere a San Juan de Rioseco) un 
Tramas del reclutamiento y participación de niños en el conflicto armado colombiano

oficial venía diariamente a decirme que me tenía que volver conservador o que si no la orden era la de matarme, y yo siempre le contestaba, que me mataran. Estas cosas llegaron hasta los oídos del general Santiago López que era el comandante de las fuerzas y me mandó llamar para decirme que me volviera conservador, pero yo seguí insistiendo en que no, que me mataran, hasta que el general me dijo que si aceptaba no volarme, él me nombraba su ordenanza. Yo me puse feliz y acepté, y me volví un pillo altanero que pedía que me dejaran ir en las comisiones de vigilancia, y armado de fusil llegaba a las fincas y les decía a las señoras, que por orden del general le tenía que mandar las mejores gallinas y, a pesar de las protestas, me bajaba y machete en mano las despescuezaba, amarrándolas de las patas a la cabeza de la silla. De cada salida regresaba con cuatro o cinco gallinas que me comía con otros soldados. (p. 240)

Como combatientes. Esta actividad podía ejecutarse de dos maneras, como parte de una fuerza regular con obligaciones y deberes militares permanentes, o como parte de los cívicos, que eran organizaciones paramilitares que no se arriesgaban en el combate, ya que solo lo hacían cuando la población era atacada. En relación con la primera forma de participación se ofrece el siguiente ejemplo:

Lo normal era que los niños estuvieran dispersos en las diferentes fuerzas operativas, aunque en algunas oportunidades estos se concentraron en grupos especiales donde las edades llegaban hasta los 10 años, como aconteció en las tropas que defendían los buques del gobierno, "Puerres", "Ibagué" y "Carazua" que operaron por algún tiempo entre Honda y Girardot. Este grupo de niños que tenían entre 10 y 12 años eran de tan escasa estatura que no alcanzaban a disparar a través de las rendijas de las trincheras de los barcos. Igualmente, la $3^{a}$ compañía del batallón cazadores que el gobierno tenía operando en Santander estaba compuesta en su totalidad por muchachos menores de 16 años. (Jaramillo, 2007, p. 242)

En la anterior narrativa, los hechos se refieren a la vinculación de niños por parte del Estado, lo que deja claro que no era una práctica solo de los grupos insurgentes. La temporalidad cronológica se ubica en menores 16 años. La espacialidad se refiere a una zona donde operaba uno de los puertos más importantes para el país, por lo tanto, se puede inferir que los niños eran usados para defender y vigilar este corredor comercial, estratégico para la economía nacional. Sobre la espacialidad, Sánchez (2008) afirma que los territorios más afectados en este periodo fueron las zonas rurales y las cabeceras urbanas, por lo tanto, los niños reclutados como soldados eran en su mayoría campesinos. Jaramillo (2007) ubica las mayores zonas de reclutamiento en los Santanderes, aduciendo que fue un batallón de niños nortesantandereanos entre los 15 y 17 años, los que murieron en el combate de Palonegro. 


\section{Los chinos de la calle}

Las guerras bipartidistas se han considerado como el quiebre de la alianza entre liberales y conservadores para derrocar al Estado. Sánchez (2008) postula que el periodo en el que se da el conflicto entre liberales y conservadores corresponde a un tránsito entre las guerras civiles del siglo XIX y la época de la violencia, dinámica que está caracterizada por la configuración de un movimiento obrero independiente como fuerza alternativa, "marcado por influencias tan dispares como la tercera internacional, el anarquismo español y las nuevas corrientes de la doctrina social católica” (Sánchez, 2008, p. 25), también por la emergencia de las luchas campesinas, representadas en los sindicatos agrarios, particularmente de la zona cafetera, y por la participación del pueblo en la esfera pública, ya fuere como invitado, excluido o ungido como protagonista en la construcción de una prometida sociedad antioligárquica.

Por su parte, Guzmán, Fals y Umaña (2010) reconocen que, en este periodo, la etapa más conflictiva fue en 1930, en las zonas de Santanderes y Boyacá, y que involucró con menor impacto Cundinamarca, Antioquia y el occidente de Caldas. Los motivos que dan pie a esta etapa es "el cambio de gobierno o quizás como último gesto de nuestro quijotismo pendenciero de los mil días" (Guzmán et al., 2010, p. 38).

La literatura acopiada para el estudio de este periodo no da cuenta del papel de los niños de manera directa en las guerras bipartidistas, pero sí se reconoce que como consecuencia de la Guerra de los Mil Días se da un crecimiento en el índice de abandono de niños en la capital del país; así lo ilustra Pachón (2007), al referirse a la fundación de la Casa de Corrección de Paiba, para la autora,

\footnotetext{
Sus inicios se relacionan con las dimensiones que adquirió el problema de la vagancia y la delincuencia infantil en la capital al final de las guerras civiles, especialmente al concluir la Guerra de los Mil Días, y con el clamor de la ciudadanía por que se estableciera una institución carcelaria destinada especialmente para niños. (p. 325)
}

De acuerdo con lo anterior, si bien el país se embarcaba en un nuevo conflicto, el bipartidista, se inicia todo un programa de gobierno que pretendía la "civilización” de los niños abandonados. Para ello se dirigen algunos recursos para la construcción de casas correccionales.

La temporalidad en las tramas de este periodo se configuran en las edades de los niños primitivos, los llamados "chinos de la calle", quienes eran castigados como cualquier adulto si superaban los 7 años (Pachón, 2007). Se cree que en Bogotá creció la población de niños abandonados, por el éxodo de familias a la ciudad, a causa de la guerra bipartidista que en el campo se recrudecía. Las familias desplazadas no tenían cómo sobrevivir o mantener a sus 
Tramas del reclutamiento y participación de niños en el conflicto armado colombiano

hijos, lo que los obligaba a abandonarlos a su suerte, o por el contrario, los niños terminaban perdiéndose en la inmensa ciudad y sus familias nunca los encontraban.

La espacialidad que configura la trama de esta época se ubica netamente en la escuela, pues ésta sufrió una reforma para cumplir con las intenciones de normalización e higienización. Saldarriaga y Sáenz (2007) refieren a dicha reforma, como un "proceso de modernización” de los métodos de disciplina, con la implementación del modelo de la escuela activa. Estos autores explican las discontinuidades en las concepciones sobre la infancia propias de las cuatro primeras décadas del siglo XX que se encuentran vinculadas con la educación: teoría de la degeneración de la raza colombiana, la cual consideraba que los pobres tenían una serie de anormalidades, que eran detectables y superables en la escuela; medicalización de la escuela pública, que permitía un mayor control de emociones y fantasías en la escuela, dominar la "pasividad y pereza” propias del pueblo, y la ampliación de los años de escolaridad, lo que llevaría a una mejor adaptación a las sociedades modernas por parte del niño; apropiación de las ciencias de la vida en la pedagogía colombiana, que permitió que la antropología y la sociología complementaran la mirada medicalizada de la escuela; y la institucionalización de las prácticas de la escuela activa o escuela nueva, como una forma de considerar la sociabilidad como una habilidad que potenciaba la escuela.

\section{Los niños rojos y azules de la época de la violencia}

Respecto a la época de la violencia (1945-1964), Sánchez (2008) reconoce que estuvo caracterizado por tres hechos: 1) desmantelamiento a sangre y fuego de la rebelión de abril que revindicaba el desborde de las guerras bipartidistas; 2) el uso de dispositivos ideológicos, legales y de coerción encaminados a desalentar las organizaciones obreras y todo intento de protesta cívica y social; y 3) la "generalización de la represión en la remota provincia, que adquiere visos de cruzada de exterminio contra el gaitanismo y demás variantes de la izquierda política primero, antes de extenderse a todo el partido liberal después” (Sánchez, 2008, p. 31).

Los atributos de los personajes, nombrados simbólicamente, fueron:

- Los chulavitas o pájaros, quienes eran policías del estado conservador y ejecutaban acciones en contra de los liberales.

- La chusma, quienes eran los guerrilleros liberales.

- Los bandoleros, que eran disidentes de la guerrilla liberal o de la policía conservadora (pájaros o chulavitas), quienes una vez firmado el acuerdo de paz sufrieron desarraigo y no tuvieron la capacidad de reintegrarse a la vida civil, por lo que se dedicaron al asesinato a sueldo al servicio de los chulavitas. Es importante resaltar que lo simbólico de sus nombres (Capitán Veneno, Chispas, El Tigre, Sangre Negra, Desquite, Alma Negra, Zarpazo, Capitán Venganza), representaba fielmente sus acciones. Algunos de estos personajes fueron reclutados cuando eran niños. 
En cuanto a la temporalidad cronológica, se tiene que para este periodo eran reclutados niños menores de 16 años. Particularmente, el bandolero Teófilo Rojas, alias Chispas, tenía 12 años cuando huyó después de presenciar el asesinato de toda su familia en el caserío de Guadalito de Rovira, en 1950, quien "se destacó desde niño por su carisma, orden y valentía en el combate. A pesar de su corta edad le fueron encargadas misiones de confrontación con la policía” (Delgado, 2011, p. 61).

Sánchez y Meertens (2002) recogen el testimonio de Murió, un niño que fue reclutado por alias Chispas:
Mi papá estaba en Ibagué viendo unas cargas de cebolla y como a eso de las 10 de la noche llegó la policía preguntando por mi papá, entonces me amarraron a un palo de café y ahí mismo mataron a mi mamá porque había llorado el día que mataron a Gaitán. Cuando yo estaba en Quebradanegra trabajando llegaron unos muchachos amigos míos que también les habían matado los papás, que nos fuéramos para el monte porque no podíamos trabajar pues si no éramos trabajadores conservadores, de todas maneras no nos dejaban tranquilos y vivíamos amenazados. Nos fuimos para el Remanso que es de Pijao para arriba, casi llegando a Planadas, Tolima; éramos como unos doscientos armados unos con fusil, pistolas carabinas, revólveres, al mando del "General Alias Peligro”; unas veces peleábamos con la policía que era muy mala en ese tiempo y otras veces trabajamos la agricultura (...). Por la mañana hacíamos orden cerrado al mando del teniente “Arboleda” que está en el cañón de las Hermosas y después salíamos a comisionar en grupos de 10 en 10 por las veredas cercanas a Rioblanco, Carco, El Limón, Campohermoso, El Cerro de la Estrella, El Davis y la Herrera. (p. 105)

En el anterior relato se puede distinguir que los hechos corresponden a una confrontación entre liberales y conservadores, cuya consecuencia es la orfandad de cientos de niños y niñas, que toman la determinación de armarse como una única posibilidad de sobrevivir. En cuanto a la temporalidad, se puede inferir que la experiencia humana que se relata está puesta en el antes del reclutamiento y en la participación en el grupo armado, en tanto se describe cómo se vincularon y las tareas particulares que se debían cumplir. El relato de Murió, deja ver una espacialidad de coordenadas que enmarcan la región del Tolima.

El grupo de los bandoleros no era el único grupo que reclutaba menores, pues varios autores (Sánchez, 2008; Álape, 1989) afirman que Pedro Antonio Marín, alias Tirofijo, ingresó a las guerrillas liberales a los 17 años y, posteriormente, fundó las Fuerzas Armadas Revolucionarias de Colombia -FARC-. 
Tramas del reclutamiento y participación de niños en el conflicto armado colombiano

\section{Los primeros niños guerrilleros}

En este periodo los hechos están configurados por la fundación de las dos más grandes guerrillas del país, las FARC y posteriormente del ELN, guerrillas emblemáticas, que más que luchar por la reforma agraria, consolidaron ideales comunistas y socialistas.

Medina (2010) reconoce que las FARC-EP, nacieron como acción de resistencia armada por parte de un núcleo de campesinos ante la operación Marquetalia, que consistió en la recuperación por parte del Estado de las regiones de Marquetalia, Riochiquito, El Pato, Guayabero, Sumapaz y la región del Ariari, las cuales se consideraban "liberadas" por la presencia de las autodefensas campesinas y la poca atención estatal.

Por su parte, el ELN hace su primera incursión armada el 7 de enero de 1965, con la toma de Simacota, un pueblo de Santander. Allí dan a conocer el "Manifiesto de Simacota", un documento en el que se erigen sus derroteros de lucha: la revolución como único camino para lograr cambios que favorezcan a las mayorías, la lucha por el poder en tanto lucha de clases, la lucha por la liberación nacional ante la intromisión de capitales y poderes extranjeros, y la consigna acerca que la lucha es de todo el pueblo, no solo del proletariado.

Para este periodo, se tiene evidencia del reclutamiento de niños en las filas de la guerrilla, con la inserción de Manuel Rodríguez Bautista, alias Gabino, quien ingresó a la edad de 12 años de manera voluntaria y con la autorización de sus padres, según sus palabras, sintiéndose como cualquier otro niño cuando se desprende de sus padres para ir al colegio (Vergara, 2007).

En relación con los atributos de los personajes, Vergara (2007) documenta que para los guerrilleros los niños eran como las "abejas", porque picaban antes de que se posicionara el enemigo. Este simbolismo es importante, pues se dota a los menores de características necesarias para la guerra, como ser pequeños y ágiles, salir "volando” para escaparse del enemigo, causar daño en su ataque y difícilmente ser atrapados.

La temporalidad desde el tiempo histórico se configura con la experiencia de los niños emblemáticos que se vincularon y participaron de los grupos armados de la época, pues algunos de ellos fueron quienes dieron auge a las ideologías revolucionarias y, posteriormente, fueron los dirigentes reconocidos de los grupos armados.

Por su parte, la espacialidad, como coordenada, no está limitada a regiones particulares del territorio nacional, por el contrario, las confrontaciones armadas entre los revolucionarios y el ejército se extendieron por todo el país. 


\title{
Los primeros niños paramilitares
}

En este periodo se dieron dos tipos de vinculación de los niños al conflicto armado. Por una parte, en las zonas urbanas, y dado el auge del narcotráfico, se dio el fenómeno de los niños sicarios, y por otra, en las zonas rurales, con la creación de las Autodefensas Unidas de Colombia, con el reclutamiento de menores a este grupo armado. En cuanto al primer fenómeno, los niños sicarios, Medina, Vargas, Medina y Jaramillo (2010) afirman que dos grandes novedades impulsaron el narcotráfico de los años 80,

\begin{abstract}
Una, su creciente infantilización: sus edades han pasado de los 15-16 años a los 10-13. Y otra, la incorporación al sicariato de adolescentes acogidos en la última década a los programas de desmovilización, que llegan así con "adiestramiento militar y de insurgencia. (p. 14)
\end{abstract}

Como atributo de los personajes, Vergara (2007) afirma que los escuadrones de paramilitares llamaban a los niños vinculados a sus filas "campanitas", porque los usaban para dar avisos de alarma, y porque muchas veces fueron usados como carne de cañón cuando eran enviados al frente de combate, alertando a los adultos combatientes que tenían que recular o dando tiempo para el avance seguro.

Otros atributos, son los tratados por Medina et al. (2010), quienes reconocen que el niño sicario de la época se consideraba como la víctima social, convirtiéndolo en una especie de mito y héroe picaresco (...). "El sicario es presentando como una pieza más de la larga cadena que integra el narcotráfico, vinculando el negocio de la muerte con todas las esferas de la sociedad” (Medina et al., 2010, p. 12).

Como parte del análisis se presentan dos casos. Uno es el siguiente relato de un niño sicario a principios de los años 90:

Recuerdo la primera vez que me tocó matar. Yo había herido a personas pero no conocía los ojos de la muerte. Sucedió, un día por la mañana, en Copacabana, un pueblo cercano a Medellín. Estábamos robando una casa-finca y sin saber de dónde se nos apareció el celador. Yo, desde mi escondite, detrás de un muro, asomé la cabeza y de puro susto le metí por la espalda los seis tiros del tambor. El hombre quedó frito de una. Eso fue duro, pa' qué le miento, muy duro. Pasé quince días que no podía comer porque veía al muerto hasta en la sopa... pero después se me hizo fácil, aprendí a matar sin que eso me molestara el sueño. Eso de matar es una cuestión que se vuelve normal. Lo mejor es matar gente que las debe, que ha sido grosera. O gente que uno no conoce. Es más difícil que me apunte a cascarle a alguien conocido. No tanto por culillo, 
Tramas del reclutamiento y participación de niños en el conflicto armado colombiano

al fin uno se acostumbra, sino porque es mal negocio dejar culebras en todas partes. (Carballal, 2007, p. 112)

En la crudeza del anterior relato, muestra como atributos del niño que narra el paso del miedo a la valentía, en su lógica. Al parecer, el ritual de la primera vez que se mata permite que el personaje asuma otro carácter, el de una persona con experiencia.

Por su parte, la temporalidad en el relato deja ver un tiempo humano, en el que "yo hago" se reconoce una subjetividad particular, en este caso, cuando el niño narra que roba y mata, está narrando su subjetividad como sicario. La espacialidad de esta narración se relaciona con la región de Medellín, en la que históricamente se reconoce que hubo auge de niños sicarios por la confluencia de condiciones sociales y económicas.

El segundo caso de análisis para este periodo es el de los niños reclutados por Ramón Isaza, un conocido paramilitar que desobedeció las órdenes de Pablo Escobar para expandir los cultivos ilícitos y tener el control en Puerto Boyacá y Puerto Triunfo. A principios del 2006 este paramilitar se desmovilizó con cerca de 1000 hombres, entre ellos varios niños (Pacto de Ralito). A Isaza se le acusa de tener un frente paramilitar constituido por solamente niños, suscrito a las Autodefensas Campesinas del Magdalena Medio (ACMM). En el periódico Nuevo Día ${ }^{1}$ del departamento delTolima se hace referencia al expediente legal de Isaza, el cual menciona algunos de los menores desvinculados de este grupo, todos menores de 17 años, campesinos y de baja condición socioeconómica, lo que en la mayoría de los casos se explica como una artimaña del grupo paramilitar para seducir a los niños con la promesa de sueldos fijos.

La temporalidad se exhibe desde la cronología de la edad de quienes fueron reclutados (menores de 17 años), y desde la experiencia que implicó ser paramilitar. El tiempo histórico se reconoce en la huella que dejó el Pacto de Ralito para la historia del país, permeado por escándalos de corrupción y complicidad de la alta clase política con la delincuencia.

Por su parte, la espacialidad, en los casos de vinculación de menores por parte de Ramón Izasa, se da en las coordenadas del departamento de Antioquia, lo que permite reconocer que, este frente compuesto por niños, se vinculó con los sicarios de Medellín.

\footnotetext{
${ }^{1}$ La información ha sido tomada de http://www.elnuevodia.com.co/nuevodia/especiales/generales/225229-el-ejercito-deninos-de-las-autodefensas-de-ramon-isaza. Fecha de recuperación: septiembre 25 de 2015.
} 


\section{Conclusión}

El recorrido por el conflicto colombiano deja ver que la trama narrativa del reclutamiento y participación de niños no es nueva, por el contrario, es un fenómeno que al parecer hace parte de las dinámicas degradadas de la guerra de varias décadas. Particularmente, en Colombia con un conflicto de más de un siglo, al reclutamiento de niños en las filas de los grupos armados se suman otros factores como la pobreza, la falta de oportunidades, falta de empleo y educación, y la ausencia de la fuerza pública y otras instituciones en zonas vulnerables.

Los atributos de esta trama se relacionan con los hechos de pobreza del territorio nacional, así como la no atención a la niñez. Se reconoce que los niños ingresan a los grupos armados por vengar la muerte de algún pariente a manos del grupo enemigo, o por subsistencia, después de sufrir la orfandad.

Los personajes de esta trama son niños menores de edad. Los atributos de estos personajes están dados por ser niños osados, sin miedo, valientes, temerarios, lo que supuestamente se consideran buenas características para quienes participan de la guerra; sin embargo, estos atributos parecen ser atribuibles a lo biológico y a lo psicológico, a la condición propia de ser niño, de quienes no han vivido lo suficiente para medir los peligros. Además su contextura física permite que se escabullan o camuflen fácilmente. Para los grupos armados es más económico tener un niño en sus filas, pues come menos y se le puede pagar, si es el caso, mucho menos que un adulto.

Otra característica particular de los personajes de los ejemplos expuestos en el análisis es que son campesinos, muchos huérfanos como consecuencia de la misma guerra. En los relatos analizados se puede considerar que se presenta un tiempo lineal, donde quien narra reconoce un inicio, un nudo y un final; además el tiempo calendario está caracterizado por la edad cronológica de los personajes, para los casos analizados, todos menores de edad. El tiempo humano es relevante en los relatos, cuando se narra lo que se puede hacer (yo hago) como conservador, liberal, paramilitar o guerrillero, pero sobre todo en la subjetividad que se identifica con el grupo (yo puedo). En los relatos analizados el yo puedo está mediado con las acciones crueles (torturas, asesinatos), que se pueden ejecutar como parte de un grupo armado. Finalmente, el tiempo histórico de los relatos analizados deja ver la imborrable huella de horror que ha dejado la guerra en distintas generaciones, y que sin duda son los niños, sin importar la época, quienes con mayor impacto han sufrido las consecuencias de la degradación de la guerra.

En cuanto a la espacialidad, se puede afirmar que las coordenadas geográficas en las que se ha desarrollado la confrontación armada, corresponde a todo el territorio nacional sin excepción, sin embargo, se reconoce que en las regiones rurales es en donde la vinculación y participación de menores se exacerba. 
Tramas del reclutamiento y participación de niños en el conflicto armado colombiano

Finalmente, el acercamiento narrativo a las experiencias de los sujetos permite entender los alcances de una guerra que ha degrado al límite la condición humana, y que para el caso colombiano, ha impactado la persona de miles de niños por generaciones, cuyas memorias requieren del concurso de la sociedad entera para comprender lo que ha pasado y para alinear voluntad para esas situaciones no vuelvan a repetirse.

\section{Referencias}

Álape, A. (1989). Las vidas de Pedro Antonio Marín. Manuel Marulanda Vélez. Tirofijo. Bogotá, Colombia: Planeta.

Bolívar, A. (2002). “¿De nobis ipsis silemus?”: Epistemología de la investigación biográficonarrativa en educación. Revista Electrónica de Investigación Educativa, 4 (1). Recuperado de file: / / C: / Users/22B010/Downloads/49-239-1-PB.pdf.

Carballal, M. (2007). Los niños sicarios de Medellín. Recuperado de http://manuelcarballal. blogspot.com.co/2007/04/los-nios-sicario-de-medelln.html.

Delgado, J. (2011). El bandolerismo en el valle del Cauca 1946-1966. Cali, Colombia: Autores Vallecaucanos.

Guzmán, G., Fals, O. y Umaña, E. (2010). La violencia en Colombia. Estudio de un proceso social. Bogotá, Colombia: Carlos Valencia Editores.

Jaramillo, C. (2007). Los Guerreros Invisibles. El papel de los niños en los conflictos civiles del siglo XIX en Colombia. En P. Rodríguez. y M. Manarelli. (Eds.), Historia de la infancia en América Latina (pp. 231-246). Bogotá, Colombia: Universidad Externado de Colombia.

Medina, C. (2010). FARC-EP y ELN. Una historia política comparada (1958-2006) (tesis de doctorado). Universidad Nacional de Colombia, Bogotá, Colombia.

Medina, M., Vargas, E., Medina, N. y Jaramillo, L. (2010). Autorretrato del sicario (tesis de especialización). Universidad Católica Popular de Risaralda, Pereira, Colombia.

Pachón, X. (2007). Historia de la infancia en América Latina. Bogotá, Colombia: Universidad Externado de Colombia.

Pécaut, D. (2006). Crónica de cuatro décadas de política colombiana. Bogotá, Colombia: Editorial Norma.

Quintero, M. (2010). Investigación narrativa estrategia metodológica. [Documento inédito].

Ricoeur, P. (2010). Educación y política. Buenos Aires, Argentina: Prometeo.

Saldarriaga, O. y Sáenz, J. (2007). Historia de la infancia en América Latina. Bogotá, Colombia: Universidad Externado de Colombia. 
Sánchez, G. (2008). Guerra y política en la sociedad colombiana. Bogotá, Colombia: Santillana.

Sánchez, G. y Meertens, D. (2002). Bandoleros, campesinos y gamonales. Bogotá, Colombia: El Áncora.

Vergara, O. (2007). Ritos de paso en tiempos de guerra: el reclutamiento de niños, niñas y jóvenes en el conflicto armado en Colombia. En P. Rodríguez. y M. Manarelli. (Eds.), Historia de la infancia en América Latina (pp. 577-590). Bogotá, Colombia: Universidad Externado de Colombia. 